\title{
O Controvertido Uso Das Teleperícias Em Tempos De Isolamento Social Pela Pandemia De Covid-19
}

\author{
Alan da Costa Macedo * \\ Universidade Católica de Petrópolis, Programa de Pós-Graduação em Direito, Petrópolis-RJ, Brasil. \\ (iD https://orcid.org/00oo-0003-3598-3345 \\ Bruno da Silveira Pataro Moreira ** \\ Universidade Católica de Petrópolis, Programa de Pós-Graduação em Direito, Petrópolis-RJ, Brasil. \\ iD https://orcid.org/0000-0002-7060-135X \\ Rodrigo Grazinoli Garrido \\ Universidade Católica de Petrópolis, Programa de Pós-Graduação em Direito, Petrópolis-RJ, Brasil
}

in https://orcid.org/0000-0002-6666-4008

Resumo: O presente artigo tem por objetivo apresentar algumas reflexões lógicoindutivas baseadas na normatividade das ciências forenses, em especial das perícias médicas judiciais, relacionadas à concessão de benefícios previdenciários por incapacidade em tempos de isolamento social pela pandemia de COVID-19. Analisase a possibilidade da utilização do instituto da teleperícia, sobretudo em psiquiatria, à luz dos comandos normativos vigentes e dos órgãos e autoridades ligadas ao Poder Judiciário em contraposição às diretrizes do Conselho Federal de Medicina. Partiuse da compreensão da perícia médica como meio de prova e, portanto, como matéria regulada primariamente pelo Direito Processual Civil e pela Constituição Federal. Nos resultados obtidos, concluiu-se que é legal e ética, além de tecnicamente possível em vários casos, a utilização da teleperícia em situações que imponham barreiras que dificultem o acesso ao exame presencial, ficando a cargo do perito médico e do periciando opção pela realização do atendimento telepresencial.

Palavras-chave: Perícia psiquiátrica. Perícia previdenciária. Prova técnica. COVID-19.

\footnotetext{
* Mestrando em Direito pela Universidade Católica de Petrópolis (PPGD/UCP). Oficial de Gabinete na Vice-Presidência do TRF-1. Professor do Instituto de Estudos Previdenciários (IEPREV). Graduado em Biologia. Graduado em Direito. E-mail: alanprofessordireito@gmail.com

*** Mestrando em Direito pela Universidade Católica de Petrópolis (PPGD/UCP). Médico com atuação em Perícias Psiquiátricas. Advogado. E-mail: bpataro@gmail.com

*** Perito Criminal da Polícia Civil do Estado do Rio de Janeiro no Instituto de Pesquisa e Perícias em Genética Forense-IPPGF. Professor Adjunto da Faculdade Nacional de Direito-FND/UFRJ e da UCP nos Cursos de Graduação em Direito e Biomedicina e no Programa de Mestrado em Direito-PPGD da UCP. E-mail: grazinoli.garrido@gmail.com
}

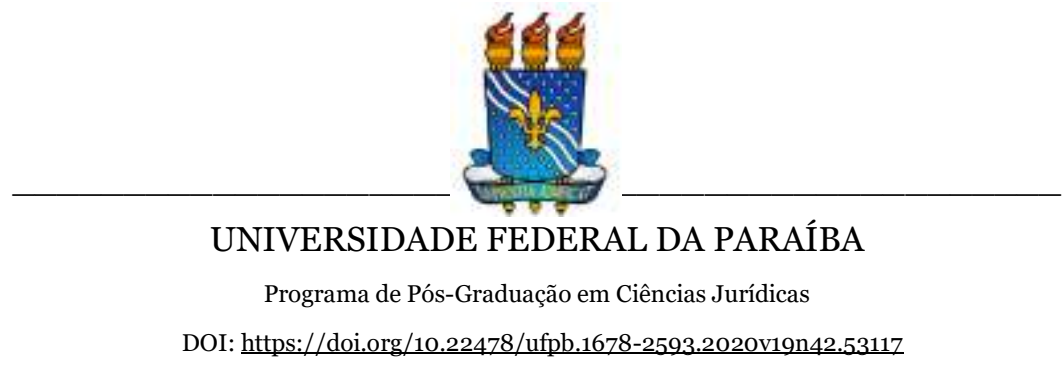




\title{
O Controvertido Uso Das Teleperícias Em Tempos De Isolamento Social Pela Pandemia De Covid-19
}

\author{
Alan da Costa Macedo \\ Bruno da Silveira Pataro Moreira
}

Rodrigo Grazinoli Garrido

\section{INTRODUÇÃO}

No que se refere às ações judiciais que tem por objeto os benefícios concedidos pelo regime geral de previdência, principalmente os relacionados à incapacidade laboral, o processo judicial ganha contornos especiais, tendo em vista que os benefícios previdenciários têm natureza "alimentar", sendo o bem jurídico protegido relativo à subsistência, com contingência social prevista em lei.

Assim, em busca da concessão judicial, a partir do indeferimento pelo INSS, deve-se passar, necessariamente, pela realização de um outro exame pericial. Desta vez, porém, a análise é feita por um médico imparcial e de confiança do juízo, o qual, aos quesitos do magistrado e das partes, realiza o múnus público de grande importância, a perícia médica judicial (MACEDO, 2017).

A perícia médica judicial é, nesse sentido, um meio de prova, de natureza investigatória, junto à administração judiciária, que se apresenta como matéria de imprescindível necessidade probante seja no interesse imediato do desvendar de litígios, seja na sua função precípua de fornecer elementos ao juízo para o alcance da verdade dos 
fatos. Desse modo, a prova pericial adquire sempre uma dimensão da mais notória valia (MACEDO, 2017).

Contudo, várias polêmicas em torno da atividade médicopericial no âmbito judicial têm marcado os debates entre os juristas e os médicos, já que a ciência "Perícia médica" é classificada como uma ciência híbrida ou uma espécie de ponte entre Direito e Medicina (ALMEIDA, 2017). A mais recente guarda relação com a necessidade de realização da perícia médica presencial para concessão de benefícios previdenciários por incapacidade, em detrimento da impossibilidade técnica e logística decorrente do isolamento social determinado em função da disseminação do novo coronavírus (2019$\mathrm{nCoV}$ ) e da pandemia da doença causada, a COVID-19 (GARRIDO e GARRIDO, 2020). As inquietações trazidas pelos diversos protagonistas da atividade jurisdicional relacionadas à mais nova polêmica, foi enfrentada como tema central do presente trabalho.

Movidos pela interrupção dos trabalhos presenciais, em decorrência da declaração de emergência em saúde pública de importância internacional, em 30 de janeiro de 2020, e pela de pandemia, em 11 de março de 2020, ambas pela Organização Mundial da Saúde - OMS, os Tribunais Regionais Federais e suas seccionais editaram Resoluções e Portarias suspendendo a realização de perícias judiciais e demais atos processuais que demandassem a presença física de partes, procuradores ou servidores.

Quanto aos atos processuais urgentes, estes foram mantidos. Todavia, os que dependem da realização de perícias médicas permaneceram suspensos, o que reclamou diversas reuniões de trabalho com a participação de juízes e servidores que atuam na matéria previdenciária e com perícia médica, objetivando deter mais informações sobre o problema.

Além das diversas notas técnicas emanadas dos institutos e conselhos de classe, sobrevieram atos normativos do Poder Judiciário e do Ministério Público, orientando a realização de teleperícias no contexto do processo Judicial previdenciário. De outro lado, o 
Conselho Federal de Medicina manifestou-se, reiteradamente, contra a utilização daqueles estudos sob as razões que serão investigadas no presente trabalho.

Nesse contexto, além de se pesquisar questões jurídicoprocessuais relacionadas à perícia médica, deve-se buscar explicações interdisciplinares sobre as questões éticas e profissionais inerentes à atividade médico-pericial, inclusive a partir de fontes alienígenas.

Segundo Garrido e Portes (2016), é cediço que, apesar de inexistir hierarquia entre provas, na maioria das vezes, a prova pericial presencial acaba sendo um tipo de "última palavra" sobre o objeto investigado nos autos de um processo judicial. Por conseguinte, não se pode menosprezar a sua relevância e a sua eventual substituição por outros meios de prova análogos em tempos anormais.

O que se quer extrair, neste trabalho, a partir de um diálogo de fontes normativas e dogmáticas é se, diante da situação de exceção, ou seja, do quadro atual de pandemia do COVID-19, a utilização da teleperícia seja viável ou se apenas em algumas especialidades médicas, tal como a psiquiatria, ela seja possível.

Para tal construção, no entanto, é necessário chamar o leitor, no primeiro momento, a entender a diferença entre os institutos da telemedicina e o da teleperícia. Numa segunda etapa, aborda-se o conceito doutrinário da perícia médica, cotejando-o com a ausência de legislação ordinária que a conceitue e a regulamente em todas as suas vertentes de aplicação.

No terceiro momento, realiza-se uma breve abordagem sobre o poder regulamentar do Conselho Federal de Medicina e o conceito de perícia médica extraído de suas normas. Já, na quarta etapa do trabalho, aborda-se o conteúdo da Resolução no 317/2020 do CNJ sobre Telemedicina e Teleperícia e das notas técnicas que lhe serviram de base. E, no quinto e último ponto, analisa-se, sob o prisma da prática em perícias psiquiatras, as possibilidades do uso da telemedicina no contexto da especialidade médica psiquiatria.

Em linhas conclusivas, será possível, de forma dedutiva, opinar se é possível, sob uma análise jurídico-dogmática e sob o regime de 
O Mundo Do Trabalho Em Tempos De Pandemia No Brasil: 0 Incremento Da...

exceção que se apresenta no âmbito jurisdicional, a utilização da teleperícia em detrimento da perícia médica judicial tradicional. Para além disso, conclui-se sobre a vinculação dos médicos peritos aos atos emanados dos órgãos ligados ao Poder Judiciário, sob a observâncias dos princípios e normas relacionados ao exercício profissional.

\section{TELEMEDICINA E TELEPERÍCIA - QUESTÕES CONCEITUAIS E NORMATIVAS}

O Conceito de Telemedicina dado pela Organização Mundial da Saúde (OMS) está relacionado a um tipo de oferta de serviços de cuidados à saúde humana, tais como: prevenção e tratamento de doença; educação dos provedores de cuidados à saúde; pesquisas e avaliações em saúde; todos com o intuito de melhorar a saúde das pessoas e das comunidades em que vivem (OMS, 2010).

No Brasil, um dos primeiros capítulos normativos da Telemedicina decorreu da Resolução 1.643/2002 do Conselho Federal de Medicina, que definiu, em seu art. $1^{0}$, a telemedicina como "exercício da Medicina através da utilização de metodologias interativas de comunicação audiovisual e de dados, com o objetivo de assistência, educação e pesquisa em Saúde”. Tal Resolução foi revogada, em 2018, pela Resolução CFM 2.227/2018 e restabelecida pela Resolução CFM no 2.228/2019, atualmente vigente.

Em função da pandemia do Coronavírus e da necessidade de isolamento social, em março de 2020, foi apresentado o Projeto de Lei $\mathrm{n}^{0}$ 696/2020, de autoria da Câmara dos Deputados. Este veio a se transformar na Lei 13.989/2020 e dispôs especificamente sobre o uso da telemedicina durante a crise causada pelo COVID-19. O art. $3^{\circ}$ da Lei 13.989/2020 definiu telemedicina da seguinte forma: "art. $3^{\circ}$. Entende-se por telemedicina, entre outros, o exercício da medicina mediado por tecnologias para fins de assistência, pesquisa, prevenção de doenças e lesões e promoção de saúde." 
A despeito do já utilizado instituto da telemedicina para diversas especialidades médicas no Brasil, com permissão infra legal regulamentar de natureza ético-profissional por parte das Resoluções do Conselho Federal de Medicina, a especialidade médico-legal e perícias não ficaria desapercebida. Assim, diversos envolvidos na atividade judicial cogitaram a utilização do instituto da teleperícia médica durante o período da pandemia.

Em abril de 2020, o CFM, sob consulta do Conselho Nacional de Justiça (CNJ), proferiu o parecer $n^{0} 3 / 2020$ sobre o assunto "teleperícias ou perícias virtuais". Em 06 de maio de 2020 foi publicada a Resolução $n^{0}$ 317/2020 do CNJ que, contrariando o parecer do CFM, dispôs "sobre a realização de perícias em meios eletrônicos ou virtuais em ações em que se discutem benefícios previdenciários por incapacidade ou assistenciais, enquanto durarem os efeitos da crise ocasionada pela pandemia do novo Coronavírus", e deu outras providências.

Antes, porém de adentrarmos à análise dos pareceres do CFM e de outras entidades classistas relacionadas à perícia médica, convém fazer uma breve análise sobre os conceitos normativos e doutrinários de perícias médicas no Brasil.

\subsection{Conceito de Perícia Médica}

A priori, é importante ressaltar que a perícia, em termos gerais, para os fins do direito, se conforma em meio de prova à comprovação de um determinado fato jurídico que requeira investigação por parte de um profissional expert no objeto investigado. No âmbito do processo civil, o art. 464 do CPC define a perícia em meio de prova consistente em exame, vistoria ou avaliação; praticada por profissional especializado no objeto investigado. 
Para Marinoni (2015), o conceito de prova pericial foi assim delineado:

[...] a prova pericial é admissível quando se necessite demonstrar no processo algum fato que dependa de conhecimento especial que não seja próprio do "juiz médio", ou melhor, que esteja além dos conhecimentos que podem ser exigidos do homem e do juiz de cultura média. (MARINONI, 2015, p.250)

A perícia médica, não obstante ser uma espécie do gênero "perícia”, só veio a se tornar uma especialidade formal da medicina em 01/o8/2011, através da Resolução CFM no 1973/2011, que, diante do convênio de reconhecimento de especialidades médicas firmado entre aquela autarquia e a Associação Médica Brasileira (AMB) e a Comissão Nacional de Residência Médica (CNRM), criou a especialidade híbrida "Medicina Legal e Perícias Médicas".

Anteriormente ao reconhecimento da especialidade, muitos médicos já realizavam a perícia médica sem que tivessem tal especialização e, ainda hoje, assim o fazem, sob o autorizativo legal contido no art. $5^{\circ}$, II, da Lei $12.842 / 2013$, verbis: "art. $5^{\circ}$ São privativos de médico: [...] II - perícia e auditoria médicas; coordenação e supervisão vinculadas, de forma imediata e direta, às atividades privativas de médico;”.

O parecer CFM 45/2016, ao interpretar o supra mencionado dispositivo legal disse que:

O termo "especialidade" no CPC é genérico e não se refere às especialidades médicas, mas sim à área do conhecimento técnico ensejado pelo objeto da perícia. (...) Impende ressaltar que ter expertise em determinada especialidade médica não qualifica prontamente o médico para responder às questões médico-periciais. A despeito de seu conhecimento sobre a prática da assistência médica em determinada especialidade, é provável que desconheça por completo os critérios médico-periciais. Nesse sentido é que a formação em perícia médica é desejável para que o médico atue como perito. Entretanto, não há impedimento legal ou ético para que o médico, quando devidamente registrado no Conselho Regional de Medicina da sua jurisdição e que se sinta capacitado a realizar Perícia Médica, seja nomeado Jurisperito. Assim, temos o entendimento de que o cadastro de peritos especialistas de 
que trata o novo CPC (arts. 156 e 465) a ser formado pelos tribunais, se dará, no caso da medicina, pela listagem de médicos registrados no Conselho Regional de Medicina, independentemente de ter ou não RQE em medicina legal e perícia médica. (CFM, 2016, p.2)

Apesar de ser uma especialidade da medicina, não se conhece, no Brasil, uma legislação formal específica que trate das "perícias médicas", sendo seu conceito alcunhado por doutrinadores e por Resolução do Conselho Federal de Medicina.

Perícia médico-legal é, conforme França (2017):

\begin{abstract}
Um conjunto de procedimentos médicos e técnicos que tem como finalidade o esclarecimento de um fato de interesse da justiça. Ou como um ato pelo qual a autoridade procura conhecer, por meios técnicos e científicos, a existência ou não de certos acontecimentos, capazes de interferir na decisão de uma questão judiciária ligada à vida ou à saúde do homem ou que com ele tenha relação. (FRANÇA, 2015, p.13)
\end{abstract}

O professor Hélio Gomes (2004) conceituou a perícia médicolegal como sendo "todo procedimento médico (exames clínicos, laboratoriais, necroscopia, exumação) promovido por autoridade policial ou judiciária, praticado por profissional de Medicina visando prestar esclarecimentos à Justiça [...]" (GOMES, 2004, p. 14)

Perícia médica, em sentido mais amplo, segundo Alcântara (2006, p. 2), "é todo e qualquer ato propedêutico ou exame feito pelo médico com a finalidade de colaborar com as autoridades administrativas, policiais ou judiciais na formação de juízo a que estão obrigadas".

O conceito de "perícia médica" é, assim, eminentemente doutrinário. Enquanto ato de natureza jurídico-processual, a perícia médica é, portanto, um ato jurídico-procedimental que se convola em um expediente híbrido. Tem natureza jurídica probatória, pois tratase de um "meio de prova" e, também, técnico-científica, já que decorre do exercício de uma das funções atribuídas à medicina.

Diante da falta de conceituação legal do termo e da hipótese de ser um ato jurídico-procedimental, resta a dúvida sobre quem seria competente para regulá-la. Por ser ato de natureza processual, a 
O Mundo Do Trabalho Em Tempos De Pandemia No Brasil: 0 Incremento Da...

competência para legislar sobre o tema seria privativa da União, como dispõe o art. 22, I da Constituição Federal de 1988. Ou, diante do fato de ser um ato técnico-científico praticado com exclusividade pela medicina, teria o CFM, por suas normas infralegais, o poder de regular a matéria.

\subsection{O Poder regulamentar do Conselho Federal de Medicina e o conceito de perícia médica extraído de suas normas}

O Conselho Federal e os Conselhos Regionais de Medicina, instituídos pelo Decreto-lei $\mathrm{n}^{0}$ 7.955/45, são autarquias criadas pela Lei n. 3.268, de 30 de setembro de 1957, com personalidade jurídica de direito público, autonomia administrativa e financeira. Têm, em síntese, a atribuição de exercer a supervisão ética profissional em todo território nacional, acumulando função de julgadores e disciplinadores da classe médica.

Os conselhos de fiscalização profissional, mesmo sob a previsão legal, já tinham da doutrina o reconhecimento da natureza jurídica de autarquias, já que são criadas por lei; ostentam personalidade jurídica de direito público, com autonomia administrativa e financeira; e exercem a atividade de fiscalização de exercício profissional que, consoante o disposto nos artigos $5^{\circ}$, XIII, 21, XXIV da CF, é atividade tipicamente pública. Entretanto, apesar de possuírem natureza jurídica autárquica, estão, sob análise interpretativa e sistemáticas das normas, classificadas como autarquias corporativas, não integrando a Administração Pública, mas apenas está colaborando para o exercício da atividade de polícia das profissões.

O exercício da profissão médica é regulado a partir da Lei 12.842/2013. Entre as demais atividades privativas do médico, a referida legislação, em seu art. $4^{\circ}$, inciso, XII, e no art. $5^{\circ}$, II, prevê a 
realização de perícias médicas, mas não conceitua e nem normatiza procedimentos para a referida prática.

A perícia médica não é a única lacuna no exercício das atividades privativas do médico. A maioria dos atos regulamentares e pareceres dos Conselhos Federal e regionais de Medicina remetem à interpretação das consultas que lhe são formuladas ao Código de Ética médica, que é um ato normativo, formalizado por uma Resolução. Este último expediente hierarquicamente inferior às Leis ordinárias. Com isso, o Código de Ética Médica (CEM) não pode regulamentar matérias que não tenham sido previamente definidas pelo legislador ordinário e nem lhes dar interpretações mais restritivas que as dadas por aquele Poder da União.

O Código de Ética Médica anterior ao atual foi estabelecido pela Resolução CFM no 1.931/o9 e, como bem pontuado em seu sumário, no capítulo introdutório "Um Código para um novo tempo", está "subordinado à Constituição Federal e à legislação brasileira". Interessante notar que, além da referência hierárquica que a própria Resolução 1.931/o9 fazia à Constituição Federal e à legislação em geral, também demonstrava obediência aos comandos da Lei 9.784/99, que regula o processo administrativo federal. Certamente, tal referência específica se dê ao fato da sua natureza jurídica de autarquia federal corporativa. No ano de 2018, entretanto, sobreveio à Resolução CFM 2.217/2018, que instituiu o Código de Ética Médica atualmente vigente, mantendo a subserviência da norma às leis especiais que tratam sobre o exercício da profissão e dos seus Conselhos, bem como à Lei 9.784/99.

Já no seu preâmbulo, o Código de Ética Médica diz que contém as normas a serem seguidas pelos médicos no exercício da profissão, seja clínica ou administrativamente. Todavia, sempre que houver dúvida sobre a interpretação de um determinado fato no contexto médico, havendo conflito hermenêutico entre o que diz o código de ética e a legislação ordinária, a palavra final sobre o direito em debate será do intérprete da lei, ou seja, do Poder Judiciário. Uma vez que o médico deve, no exercício da profissão, seguir as normas contidas no 
O Mundo Do Trabalho Em Tempos De Pandemia No Brasil: 0 Incremento Da...

seu código de ética, mas que sejam balizadas com a interpretação de normas hierarquicamente superiores.

O Código de ética médica tem um capítulo específico para tratar da auditoria e da perícia médica. O Capítulo XI e seus artigos prelecionam as condutas e diretrizes do ato médico no exercício da atividade de auditoria e de perícia. É justamente na norma imposta pelo art. 92 da Resolução CFM 2.217/2018 - novo Código de Ética Médica - que se apresenta uma lacuna interpretativa, a qual vem gerando grandes debates sobre a possibilidade da teleperícia, quando caso fortuito ou força maior não permitam a realização da perícia presencial.

Diante da situação atual de isolamento social decorrente da pandemia do coronavírus, como dito, sobrevieram expedientes emanados do Poder Judiciário que autorizam, de forma temporária e como exceção à regra, a realização da teleperícia. Do lado oposto, o Conselho Federal Medicina, acompanhado de associações classistas dizem que não é possível a realização da perícia médica virtual. É o que analisaremos no capitulo a seguir.

\section{DA RESOLUÇÃo No N17/2020 DO $^{\text {CNJ SOBRE }}$ TELEMEDICINA E TELEPERÍCIA E DAS NOTAS TÉCNICAS QUE LHE SERVIRAM DE BASE}

Em 08 de maio de 2020, o CFM, sob consulta do CNJ e de outros órgãos e entidades (Processo-Consulta CFM No 7/2020), emitiu o parecer $\mathrm{CFM} \mathrm{n}{ }^{0} 3 / 2020$, posicionando-se contrariamente ao uso da Teleperícia ou perícia virtual. Afirmou que "O médico Perito Judicial que utiliza recurso tecnológico sem realizar o exame direto no periciando afronta o Código de Ética Médica e demais normativas emanadas do Conselho Federal de Medicina”. 
$A b$ initio, o parecer $\mathrm{CFM} \mathrm{n}^{0}$ 3/2020, assinado pela Conselheira Relatora Rosylane Nascimento das Mercês Rocha, sem citar a referência bibliográfica ou mesmo dispositivo legal ou regulamentar, passou a conceituar "perícia médica":

A perícia médica é uma ciência porque sistematiza técnicas e métodos para um objetivo determinado, que é próprio apenas dela e para atingir um objetivo que diz respeito apenas a ela e é uma Arte, porque mesmo aplicando técnicas e métodos muito exatos e sofisticados em busca de uma verdade objetiva, utiliza valores que em outras áreas do conhecimento médico não teriam a mesma interpretação. (Grifos nossos)

Como se pôde observar, o conceito de perícia médica dado pela signatária do parecer em estudo não se refere ou estabelece qualquer conexão com um ato jurídico-processual ou meio de prova em processo administrativo ou judicial. Pelo contrário, a concepção da perícia médica ali descrita remete a um ato que só se refere à própria perícia enquanto ciência ou "Arte", já que se utilizaria de "valores" que não são de conhecimento de outras especialidades médicas.

Num segundo momento, desta vez, já fazendo certa menção a um tipo de prova técnica, mas sem novamente citar adequadamente a referência utilizada, a signatária do parecer em comento, chamando atenção para a boa prática pericial, diz o seguinte:

Claude Bernard escreveu que a ciência repele o indeterminado e quando, em medicina pericial, se fundamentam opiniões na inspiração médica ou numa intuição mais ou menos vaga das coisas, estamos fora da ciência e, que a medicina pericial fantasista pode oferecer grandes perigos quando nas mãos de um ignorante inspirado. Para exercer, pois, o mister de auxiliar o Magistrado, o médico perito deverá fazê-lo com ética, rigor técnico e científico para que a prova técnica subsidie a construção da convicção do Magistrado. (Grifos nossos)

Em seguida, para fundamentar a impossibilidade da perícia por meios virtuais, ou seja, sem a presença física do periciando e do perito, o referido parecer do CFM reconhece que "Várias perícias comprovam que o motivo que originou a incapacidade e/ou a invalidez, não subsistem mais" e, ainda, que seria: 
[...] impossível avaliar déficit funcional, sequela, incapacidades ou restrições sem o exame físico direto. A préexistência do dano relativamente ao traumatismo, a natureza adequada do traumatismo para produzir as lesões evidenciadas, a avaliação da natureza adequada das lesões a uma etiologia traumática, a adequação entre a sede do traumatismo e a sede da lesão, a análise do encadeamento anátomo-clínico, análise da adequação temporal, a aplicação da semiologia na identificação de diagnóstico diferencial, a aplicação de testes contra simulação, são métodos e técnicas da ciência médica forense cuja obrigatoriedade do ato médico presencial é inarredável e irrenunciável.

Como se pode perceber, apesar dos esclarecimentos contidos no aludido parecer sobre $\mathrm{o}$ ato pericial, a generalização das impossibilidades, como avaliar o "déficit funcional, sequela, incapacidades ou restrições sem o exame físico direto" considera que toda perícia médica reclame aquelas análises.

Ressalte-se, contudo, que são diversas as demandas de aplicação do conhecimento em que se busca uma diversidade de evidências além daquelas que são propostas pelo conhecimento puramente médico. Acrescente-se, ainda, a previsão legal da prova técnica simplificada em substituição à perícia tradicional. Deve-se destacar, no entanto, que nesse caso, em tese, o exame direto do periciando telemático ou presencial não ocorreria, pois seria constituída, conforme o art. $464, \$ 2^{\circ}$ do Código de Processo Civil, "apenas na inquirição de especialista, pelo juiz, sobre ponto controvertido da causa” (art. 464, $\$ 3^{\circ} \mathrm{CPC}$ ).

Outrossim, a teleperícia é reconhecida em vários estudos publicados no exterior, em especial no que se refere à Psiquiatria (MILLER, CLARK, VELTKAMP et al. 2008; ANTONACCI, BLOCH, SAEED et al, 2008 e SALES, McSWEENEY, SALEEN et al, 2017). Todos convergem sobre a possibilidade prática do uso da teleperícia em psiquiatria.

A despeito das citadas divergências interpretativas quanto ao teor do parecer CFM 03/2020, em 14 de abril de 2020, o Ministério Público Federal oficiou ao Conselho Federal de Medicina (Oficio 128/2020/PFDC/MPF), questionando, em síntese, o seguinte: 
Com o escopo de diminuir a longa fila de requerimentos administrativos que aguardam análise pelo INSS e de dar atendimento célere aos novos requerimentos, bem como de possibilitar o andamento e desfecho das numerosas ações judiciais que discutem benefícios assistenciais e previdenciários, de forma a oferecer respostas ágeis à situação de crise instaurada pela pandemia do coronavírus (COVID-19), é preciso formular alternativas à perícia médica clássica no tocante aos benefícios assistenciais e previdenciários, visto que ela não consegue atender com a devida presteza a demanda urgente. Reitere-se que a concessão desses benefícios em caráter excepcional está sujeita à revisão posterior, tanto em âmbito administrativo, quanto judicial, apresentando-se efetivamente como medida excepcional e reversível. Com fundamento nessas considerações, a Procuradoria Federal dos Direitos do Cidadão requer que o Conselho Federal de Medicina esclareça se, em face do Parecer CFM no $3 / 2020$, considera excepcionalmente autorizada - e, a critério do médico perito, suficiente - a realização de perícia por intermédio de recursos tecnológicos, sem contato físico presencial do perito com o periciando, bem como a perícia indireta (com base em documentos médicos apresentados e outras informações consideradas suficientes pelo perito), em requerimentos administrativos e ações judiciais relativas a benefícios assistenciais e previdenciários, no contexto da pandemia causada pelo coronavírus (COVID-19). (Grifamos)

No dia 22 de abril de 2020, por meio do Oficio CFM $n^{0}$ 2252/2020, da lavra da presidência daquela autarquia, o CFM respondeu ao MPF, ratificando o parecer CFM $n^{0}$ 3/2020. Reconhecendo não existir "possibilidade de realizar perícia médica sem exame físico presencial, sob pena de afronta ao art. 92 do Código de Ética Médica, mesmo em face do estado de emergência da saúde pública de interesse internacional em decorrência da pandemia do COVID-19."

Não obstante o firme posicionamento do CFM, no dia 30/04/2020, o CNJ, sob a outorga do art. 103-B, $\S 4^{\circ}$, I, II e III, da CF, que lhe dá o poder fiscalizar e normatizar atos praticados por órgãos do Poder Judiciário, publicou a Resolução n ${ }^{0}$ 317/2020. Esta Resolução, sob a interpretação de dispositivos da Constituição Federal, de leis, de atos administrativos regulamentares e de 
O Mundo Do Trabalho Em Tempos De Pandemia No Brasil: 0 Incremento Da...

pareceres, recomendou o uso das perícias virtuais, ou seja, por meio eletrônico e, no seu art. $1^{\circ}$, parágrafos e incisos assim a disciplinou:

Art. $1^{\circ}$ As perícias em processos judiciais que versem sobre benefícios previdenciários por incapacidade ou assistenciais serão realizadas por meio eletrônico, sem contato físico entre perito e periciando, enquanto perdurarem os efeitos da crise ocasionada pela pandemia do novo Coronavírus.

$\S 1^{\circ}$ A perícia no formato estabelecido no caput deverá ser requerida ou consentida pelo periciando, a este cabendo: [...]

$\S 2^{\circ} \mathrm{O}$ perito poderá, expressamente, manifestar entendimento de que os dados constantes do prontuário médico e a entrevista por meio eletrônico com o periciando são insuficientes para formação de sua opinião técnica.

$\S 3^{\circ}$ As perícias que eventualmente não puderem ser realizadas por meio eletrônico, por absoluta impossibilidade técnica ou prática, a ser apontada por qualquer dos envolvidos no ato e devidamente justificada nos autos, deverão ser adiadas e certificadas pela serventia, após decisão fundamentada do magistrado (§ $\underline{2}^{\circ}$ do art. $3^{\circ}$ e $\S 1^{\circ}$ do art. $6^{\circ}$ da Resolução CNJ $\underline{n^{0}} 314 / 2020$ ).

O CNJ, portanto, à luz da interpretação sistemática de normas hierarquicamente superiores às Resoluções editadas pelo CFM, afirmou ser possível a realização da teleperícia em função da pandemia de COVID-19. Observe-se, ainda, que, talvez em respeito ao posicionamento do conselho de classe, bem como à autonomia do profissional médico, o $\mathrm{CNJ}$, no $\S 2^{\circ}$, do art. $1^{\mathrm{o}}$, previu que perito médico chamado ao múnus público pericial, poderá, de forma pontual e expressa, manifestar-se sobre a impossibilidade técnica de realizar o procedimento pela via eletrônica, situação em que o processo deverá aguardar até que seja viável a realização da perícia presencial.

Além disso, sempre haverá a possibilidade de se determinar nova perícia, "quando a matéria não estiver suficientemente esclarecida" (art. 480 do CPC). Assim, sopesando os limites do acesso físico em tempos de pandemia e o quanto isto pode acarretar atraso processual, a decisão pela teleperícia, a despeito de eventuais limitações, estaria sempre no sentido de garantir o andamento processual e nunca seria uma decisão irremediável. No caso de 
necessária segunda perícia, por eventual inconclusão ou deficiência da teleperícia, até mesmo os gastos podem ser reduzidos, pois se pode aplicar a redução da remuneração inicialmente arbitrada para o perito, como disposto no $\S 5^{\circ}$ do art. 465 .

Nesse contexto, cada caso, com suas particularidades e, sob a análise concreta do expert sobre os exames clínicos necessários, atestados e outros documentos médicos juntados aos autos, reclamará uma resposta sobre a possibilidade ou não da realização da teleperícia ou perícia virtual.

Após a publicação da citada Resolução do CNJ, ainda, assim, houve um ambiente de insegurança jurídica entre os médicos que atuam com perícia médica judicial: se atendessem ao chamado judicial para realização da teleperícia poderiam, em função dos pareceres emanados do CFM, sofrer processo administrativo ético.

Com base nisso, em o6 de maio de 2020, no regular exercício de suas atribuições institucionais, com base nos artigos 127 e 129, incisos II, III e VI, da Constituição da República; no artigo $5^{\circ}$, inciso I; inciso II, alínea "d"; inciso III, alínea "e"; inciso V, alínea "a", bem como no artigo $6^{\circ}$, inciso VII, alínea "a" e "c", e artigo $8^{\circ}$, II, da Lei Complementar 75/1993; na Lei 7.347/1985 e na Recomendação 164/2017 do Conselho Nacional do Ministério Público, o Ministério Público Federal publicou a Recomendação no 4/2020/PFDC/MPF, na qual, em síntese, disse o seguinte:

RECOMENDA ao Conselho Federal de Medicina que, em processos administrativos e judiciais relativos a benefícios assistenciais e previdenciários:

a) Não adote quaisquer medidas contrárias à realização de perícias eletrônicas e virtuais por médicos durante o período de pandemia da COVID-19 (coronavírus);

b) se abstenha de instaurar procedimentos disciplinares contra médicos por elaboração de Parecer Técnico Simplificado em Prova Técnica Simplificada (arts. 464 e 472 do CPC; art. 35 da Lei 9.099; art. 12 da Lei 10.259) e perícia fracionada (onde é realizado um exame de documental - parecer simplificado -, posteriormente complementado com exame físico).

ADVIRTA-SE que a presente RECOMENDAÇÃO deve ser cumprida a partir de seu recebimento, sob pena das ações judiciais cabíveis, sem prejuízo da apuração da responsabilidade civil e criminal individual de agentes públicos. 
ENCAMINHE-SE cópia da presente recomendação ao Conselho Nacional de Justiça e ao Conselho da Justiça Federal.

A propósito, um dos bons mecanismos de atuação do Ministério Público, que decorre de outorga constitucional e previsto expressamente no plano infraconstitucional é o procedimento da "recomendação", que visa a melhoria dos serviços públicos e de relevância pública, bem como ao respeito aos interesses, direitos e bens cuja defesa lhe cabe promover. Assim, apesar de não ter o condão de vincular a atuação do Poder Público, que inclui suas Autarquias, o instituto pode servir para reflexão do administrador e do administrado, contribuindo para maior segurança jurídica nos atos praticados e garantem maior previsibilidade quanto as suas consequências (SARTORI e BIALLE, 2016).

Todavia, não pode passar despercebida na recomendação a definição inadequada de "parecer técnico simplificado", como a forma de relato da prova técnica simplificada feita por perito. A despeito da temática requerer espaço maior para análise, é possível reconhecer que o perito sempre reduzirá a prova pericial a laudo, enquanto o parecer técnico seria a forma de relato feita pelo assistente técnico, como aparece, p.ex., no art. 471, $\S 2^{\circ}$ da lei processual civil ou mesmo na doutrina (LEITE, LEITE e GARRIDO, 2018)

De toda forma, diante da expedição da recomendação ou mesmo de eventual celebração do termo de ajustamento de conduta, será necessário um novo procedimento para o acompanhamento do acatamento ou não do que fora recomendado. Nesse sentido:

[...] acompanhar a implementação das recomendações abrange esclarecer se elas foram implementadas, ou seja, prosseguir na investigação dos eventuais desvios decorrentes da sua não implementação, especialmente no âmbito de um Inquérito Civil Público. Caso não haja cumprimento das recomendações, o Ministério Público deve providenciar a responsabilização cabível ou o ajuizamento da ação civil pública pertinente, sob pena de esvaziamento desse instituto processual. (ÁVILA, 2016, p. 609). 
O que se recorta, aqui, é que existe uma orientação do Ministério Público e uma Resolução do CNJ que indica a possibilidade e não obrigação da realização da teleperícia no âmbito do processo judicial previdenciário. Todavia, é cediço que os profissionais da área médica têm a liberdade de exercer sua profissão sobre as balizas técnicas que são, na maioria das vezes, forjadas em convencionamento e nos pareceres do seu Conselho Profissional.

Em termos de práticas, internacionalmente a utilização da teleperícia, ao menos na especialidade psiquiatria, é bastante relatada. Contudo, é preciso tornar clara as limitações e alcances dessa prática, como será abordado a seguir.

\section{TELEMEDICINA E TELERÍCIA EM PSIQUIATRIA - ORIGENS, CONCEITOS E DIFUSÃO}

A história da medicina se confunde com a própria história da civilização. Desde os primeiros registros de atividades que possam ser relacionadas ao exercício da medicina, o homem estuda formas de lidar com as barreiras naturais que reduzem o seu bem-estar e a sua longevidade. Desde então, a medicina vivenciou grande evolução ao longo dos séculos, tanto em seus valores éticos quanto na sua metodologia de aplicação.

Seguindo a premissa de ciência, cuja causa e razão de existir é o bem estar do ser humano, a eliminação de obstáculos que dificultam o acesso das pessoas aos profissionais da área sempre foi objeto de preocupação da ciência médica. Nesse contexto, que os conceitos de Telemedicina ou Telessaúde começaram a ganhar espaço.

A psiquiatria, enquanto especialidade da medicina, tendo em vista que lida, proeminentemente, com o comportamento humano, acaba deparando-se, quase sempre, com problemas de natureza ética e jurídica (TABORDA, CHALUB, ABDALA-FILHO, 2004). Além da 
abordagem ligada à terapêutica, os transtornos psiquiátricos também têm sido tratados como objeto de pesquisa das ciências sociais que investigam as múltiplas vertentes associadas ao sistema penal e às relações de trabalho, emprego e previdência (GARRIDO e MOREIRA, 2020).

No campo específico da psiquiatria, a consulta presencial, em alguns casos, também diante das barreiras a que sucumbem as demais especialidades (dificuldades de deslocamento, segurança, senilidade, desastres naturais entre outros), deu espaço ao progresso tecnológico e passou a se utilizar da metodologia de atendimento tele presencial. Nesse contexto, o registro das experiências internacionais bem sucedidas em telepsiquiatria tem sido importante campo de pesquisa para aplicação em solo pátrio.

Os Estados Unidos da América e Austrália são os que publicaram mais relevantes trabalhos científicos relacionados à telepsiquiatria. Os estudos australianos predominam no campo da assistência às comunidades campesinas e no atendimento de crianças e adolescentes. Os EUA, de outro lado, focam na validade clínica do atendimento sob a metodologia da telepsiquiatria em comparação com o modelo tradicional e, sob a avaliação da redução efetiva nos custos do sistema de saúde (ARANTES, 2002).

$\mathrm{Na}$ Austrália, devido ao grande território e à dificuldade de acesso ao interior do país, passou-se a utilizar a videoconferência em psiquiatria forense com a finalidade de triar e transferir pessoas com doenças mentais do sistema prisional para hospitais. Já há vinte e dois anos, desde o ano de 1998, eram feitas, em média, duas avaliações forenses em telepsiquiatria nas unidades hospitalares. Cinco anos depois, em 2003, aquele número já tinha subido para 28 do total de 47 avaliações, o que trouxe grande economia para o sistema de saúde daquele país (MARS, RAMLALL e KALISKI, 2012).

Em trabalho realizada por Sales, McSweeney, Saleen et al (2017), no Reino Unido, demonstrou-se evidências encorajadoras de que a telepsiquiatria seria um método confiável, eficaz e aceitável para 
a prestação de cuidados de saúde mental em contextos forenses. Contudo, ficou clara a preocupação em se realizar mais pesquisas para considerar as possíveis implicações legais e éticas da aplicação.

$\mathrm{O}$ uso da telepsiquiatria como alternativa também tem tido grande importância na Síria, pois devido a frequentes conflitos, esta foi a única solução possível para acesso dos cidadãos e refugiados aos médicos especialistas naquela matéria. Com a aplicações dos programas telepsiquiátricos, houve um mínimo de suporte ao estresse pós-traumático e demais patologias decorrentes dos conflitos armados do país (TSIRINTANI, ANDRIKOPOULOU e BINIORIS, 2020).

O Brasil é um país que possui uma série de peculiaridades para implantação mais efetiva da telemedicina. A extensão territorial continental; o grande número de localidades isoladas e de difícil acesso; a desigualdade regional na distribuição de recursos médicos de qualidade mínima e a notória escassez de recursos e investimentos públicos são os maiores indicadores para um potencial de expansão da telemedicina no país (MALDONADO, MARQUES e CRUZ, 2016).

Nesse contexto, a telemedicina parece ter ganho fôlego com incentivos governamentais à pesquisa na área, a partir dos anos 2000 (WEN, 2020). No ano de 2002, o Conselho Federal de Medicina publicou a Resolução $\mathrm{n}^{0}$ 1.643/2002, que definiu e disciplinou a prestação de serviços através da telemedicina. Tal ato normativo havia sido revogado em 2018, tendo sido, porém, restabelecido a vigência a partir da Resolução 2.228/2019.

Diante do reconhecimento da necessidade de implantação deste inovador modelo de assistência à saúde é que, em 2007, o Ministério da Saúde instituiu o Programa Nacional de Telessaúde. Tal programa foi ampliado em 2011, ocasião em que passou a ser chamado de "Programa Nacional Telessaúde Brasil Redes" (MALDONADO, MARQUES e CRUZ, 2016).

Outro exemplo de incentivo do governo brasileiro aos programas de telessaúde foi o que ocorreu em 2013, com o chamado "Programa Inova Saúde". Tal programa decorreu de uma iniciativa conjunta do BNDES, da Financiadora de Estudos e Projetos (Finep) e 
do Ministério da Saúde, objetivando fomentar e financiar projetos de pesquisa em instituições públicas e privadas, entre os quais se destacou o desenvolvimento de novas tecnologias de informação e comunicação aplicadas na atenção à saúde a distância (MALDONADO, MARQUES e CRUZ, 2016).

A nova tecnologia vem trazendo resultados animadores em confiabilidade, eficiência e economia. Muito deste sucesso decorre da melhoria dos meios telemidiáticos em que o profissional treinado pode observar detalhes e estabelecer o exame do estado mental com precisão próxima à avaliação presencial. Uso de aproximação, tratamento do som captado e reavaliação gravada, auxiliam a captar expressões de medo, raiva, paranoia tristeza entre outras (TSIRINTANI, ANDRIKOPOULOU, BINIORIS, 2020).

Além disso, é inegável a grande economia alcançada após a instalação do meio telemídiatico, vez que o deslocamento do especialista é extremamente dispendioso e, na grande maioria das vezes, não há disponibilidade do profissional, o qual já possui vasto compromisso em sua rotina (MARS, RAMLALL e KALISKI, 2012).

As principais limitações da telepsiquiatria estão relacionadas à impossibilidade em realizar-se o exame físico, ficando adstrito o profissional à coleta do histórico, observação do comportamento e dos exames complementares caso os tenha ou venha a fazer. Outro limitador é o próprio meio de comunicação que pode apresentar falhas, distorções ou atrasos, podendo, em raras ocasiões, prejudicar a avaliação. Por fim, a redução da conexão empática humana, que em alguns perfis de pacientes podem tornar mais dificultosa a avaliação, como exemplo de pacientes delirantes paranoicos, que podem ter seus sintomas agravados pela interação com o meio telemidiático (SALES, McSWEENEY, SALEEN et al, 2017).

Dessa forma, a adoção da nova tecnologia envolve o redesenho do processo de trabalho e por isso tem gerado tensões e conflitos, principalmente quanto a tradicional relação médico/paciente. Há resistência tanto pelo profissional, quanto pelo paciente, ocorrendo 
verdadeiras barreiras culturais, institucionais e profissionais, o que torna o processo de implementação mais lento (MALDONADO, MARQUES e CRUZ, 2016).

Além disso, um dos fatores de insegurança no Brasil é a insuficiente regulamentação normativa. Basta verificar as normas existentes (legislação ordinária; Resoluções e Portarias do Ministério da Saúde e Resoluções do CFM e dos CRM's) não trazem uma codificação completa e exauriente do assunto, o que gera insegurança jurídica e certo desconforto ao profissional médico.

Noutra vertente, estão as discussões sobre as diferenças conceituais entre Telemedicina e Teleperícia. A primeira, relacionada ao atendimento médico, à distância, em casos clínicos, com o objetivo de assistência, educação e pesquisa em Saúde. A segunda, como meio de prova, relacionada à investigação ou exame médico direto (com a presença do paciente) e indireto (a partir de documentos) para esclarecimentos de fatos em processos administrativos e judiciais.

Na Telemedicina, o médico pode, conforme dispõe o artigo $3^{\circ}$ da Resolução 1.643/2002, em caso de emergência, ou quando solicitado pelo médico responsável, emitir laudo a distância e prestar o devido suporte diagnóstico e terapêutico.

A perícia médica é, consoante a inteligência extraída dos artigos. 464 a 480 do Código de Processo Civil, um meio de prova baseado em "exame" ou "avaliação", realizado exclusivamente por médicos, para fornecer ao juízo elementos de convicção, a partir da criteriosa análise do objeto investigado. A teleperícia, seria, então, aquele exame ou avaliação realizado por videoconferência e pela análise virtual de documentos médicos.

Admitindo-se que a perícia médica e a medicina legal se conformam em uma especialidade médica, com a qual o diálogo entre Direito e Medicina torna-se essencial, o uso da teleperícia, torna-se tema de grande relevância, em especial quando se trata da perícia em Psiquiatria.

$\mathrm{Na}$ psiquiatria forense, segundo a revisão bibliográfica realizada por Sales, McSweeney, Saleen et al (2017), o uso da 
O Mundo Do Trabalho Em Tempos De Pandemia No Brasil: 0 Incremento Da...

tecnologia para análises à distância apresentou bons níveis de segurança e eficácia nas avaliações realizadas em diversos países. No mesmo estudo revisional, com relação à eficácia da telepsiquiatria forense, além da confiabilidade, apontou-se como benefícios o baixo custo e a aceitação das avaliações em diversas cortes (SALES, McSWEENEY, SALEEN et al, 2017).

Assim, partindo da percepção de que o Juiz é o destinatário da prova e que os resultados de pesquisas apontam para um bom grau de aceitação da teleperícia por parte dos Tribunais, parece ser possível a utilização deste meio de prova no Brasil.

Não se deve ouvidar, contudo, que a implantação de novas tecnologias, em especial teleinformáticas, pode ter efeito inverso, trazendo mais exclusão. Segundo Loss e Boff (2016) apesar da Previdência Social já vir, há algum tempo, buscando na internet a eliminação dos limites físicos e empoderando o usuário no processo administrativo, o favorecimento real ao aceso a esse direito fundamental perpassa pela democratização dos meios tele informáticos. O preço do acesso, a carência de redes e a falta de uma educação condizente, ainda seriam impeditivos, reclamando por uma ação efetiva do Estado na elaboração e efetivação de políticas sócioeconômicas inclusivas (LOSS; BOFF, 2026).

\section{A TELEPERÍCIA PSIQUIÁTRICA NO BRASIL}

A aplicação da teleperícia ainda é muito questionada por associações profissionais e não recomendada pelo Conselho Federal de Medicina. O principal argumento é a ausência de urgência. Isto é, consideram que, na grande maioria dos casos em que são demandadas 
perícias médicas, não se observa a possibilidade de alteração do quadro clínico do paciente com risco próximo de morte ou emergência. Por isso, não se justificaria a eventual perda de acurácia da perícia presencial com a realização da teleperícia (ABMLPM, 2020).

Apesar da conclusão do CFM contrária à teleperícia, em oportunidade anterior no Processo-Consulta $n^{0}$ 2501/10, a autarquia posicionou-se de forma inversa. Quando indagado sobre a possibilidade do uso de videoconferências nos exames periciais administrativos, realizados no âmbito do Ministério Público Federal, o CFM, paradoxalmente, emitiu parecer dizendo que: "É ética e legal a realização de videoconferência em perícias médicas administrativas, nos limites circunstanciais desta consulta, garantindo-se ao periciando o exame presencial se assim o requerer." (CFM, 2012).

A perícia médico-legal se funda em três elementos principais: 0 histórico colhido, o exame médico e os exames complementares. Como um bom entrevistador, o médico deve desenvolver a habilidade de ouvir e conduzir o diálogo para que o paciente consiga prestar informações importantes ao desenvolvimento da hipótese diagnóstica (R. NETO et al, 2009).

Durante o trabalho e na confecção do laudo, o perito fará a descrição dos fatos e atos observados, realizando uma leitura científica, conclusões e probabilidades, mantendo sempre isento e imparcial frente às partes (NAKANO, RODRIGUES FILHO e SANTOS, 2012). Na perícia médica previdenciária, a finalidade é a emissão de laudo quanto à capacidade ou incapacidade laboral, frente às situações previstas em lei, visando o enquadramento dos benefícios previdenciários (GONZAGA, 2004).

Para a avaliação psiquiátrica, em especial, são necessários principalmente dados colhidos pelo histórico médico em cotejo analítico com a aferição do exame do estado mental, isto é, a observação da apresentação e comportamento do periciando (MARTIN 1990). Inicialmente, o médico perito irá colher a identificação e a queixa principal, direcionando a linha de raciocínio para a obtenção da história. Nesse primeiro momento, é importante 
deixar o paciente o mais livre possível para falar sobre sua doença e evolução. Contudo, no decorrer do exame, é importante que o avaliador encaminhe a análise para as informações mais relevantes na construção da hipótese diagnóstica (HELZER, 1981).

Terminada a história, faz-se necessário buscar ainda informações passadas de outras doenças, desenvolvimento infantil, adolescência e idade adulta, formação da personalidade pré e pós mórbida (GOROSTIZA e MANES, 2011). Com isso, o avaliador passará para o exame psicopatológico, em comparação com as principais hipóteses levantadas. Deverá observar a aparência, lucidez, psicomotricidade, orientação, inteligência, linguagem, memória, pensamento com seu curso, forma e conteúdo, senso percepção, humor, vontade, pragmatismo, afeto, atenção e crítica (ZUARDI e LOUREIRO, 1996).

É importante destacar que a psiquiatria é uma especialidade que tem seus diagnósticos fundados na fenomenologia, ou seja, aquilo que se observa no caso atual é comparado a quadros anteriormente descritos. Assim, os exames físicos e complementares são feitos ou solicitados apenas em casos específicos e para descartar outros diagnósticos clínicos (GOROSTIZA e MANES, 2011) Nesse sentido, importante o que menciona Carlos Augusto Maranhão de Loyola (2020) em obra coletiva sobre a perícia judicial previdenciária:

[...] são poucos os casos psiquiátricos que exames complementares serão relevantes para a conclusão, havendo carência de dados objetivos para essa especialidade, deve-se tentar conduzir a entrevista de modo a agregar dados para formulação de adequado raciocínio pericial. Entrevistas mal conduzidas induzirão o periciado à simulação/sobressimulação, prejudicando a avaliação pericial, ou até confundindo o perito. (...) Resumidamente, o perito não pode esquecer que, por trás de uma sobressimulação, pode haver uma incapacidade real. E o avaliado tem que entender que o maior prejudicado no exagero dos sintomas será ele próprio. (LOYOLA, et al. 2020, p. 276)

Logo, a principal fonte de avaliação da perícia psiquiátrica é a entrevista e a observação do exame do estado mental (NETO, 2019). 
Com isso, há grande possibilidade do uso da teleperícia sem perdas significativas para a conclusão do exame. Ressalva-se os casos específicos que, eventualmente, venham requerer a realização de testes psicométricos e hipóteses diagnósticas mistas com outras áreas médicas. Nesses casos, que requeiram a análise presencial, o próprio CNJ prevê, na Resolução 317 de abril de 2020, que o perito poderá postergar o termino da avaliação e conclusão para momento em que possa ter contato diretamente com o periciado.

\section{CONCLUSÃo}

Apesar das divergências interpretativas que envolvem a definição concreta da perícia médica, o presente trabalho aponta para um ato eminentemente processual, de natureza híbrida (direito e medicina) e que pode ser melhor analisado à luz das leis processuais. Estas têm a autorização constitucional para tratar dos meios de prova e suas consequências jurídicas.

No mesmo sentido, as discussões pontuadas no decorrer do trabalho permitem um raciocínio voltado para a afirmação de que eventual celeuma entre a normas infralegais e a legislação ordinária deve ser resolvida sob o enfoque da hierarquia das normas. $\mathrm{O}$ art. 92 do Código de Ética Médica deve ser interpretado, in casu, à luz das regras estabelecidas nas legislações ordinárias especializadas e nos princípios e regras da Carta Magna de 1988.

Assim, sem entrar no mérito sobre com quem está a razão em termos técnico-científicos que envolvem a perícia médica, mas, em atenção a força normativa das Resoluções em relação à legislação ordinária e, com base na interpretação dada pelo Conselho Nacional de Justiça e pelo Ministério Público Federal ao art. 92 do Código de Ética Médica, o entendimento que deve prevalecer, por ora, é que a teleperícia pode ser realizada durante o período de pandemia do 
O Mundo Do Trabalho Em Tempos De Pandemia No Brasil: 0 Incremento Da...

COVID-19, a critério do médico nomeado para o encargo pericial, com base no art. $1^{\circ}, \S 2^{\circ}$, da Resolução ${ }^{\circ} 317 / 2020$ do CNJ.

Foi possível perceber ainda que diversos países têm conseguido utilizar com sucesso a teleperícia, reduzindo as limitações técnicas, pelo aumento da qualidade e velocidade das tecnologias de transmissão de dados. No mesmo sentido, foi possível constatar que um dos fatores que justificam e valorizam a teleperícia realizada em outros países, em especial a psiquiátrica, é o uso dessas tecnologias em locais de difícil acesso ao especialista, tais como presídios e zonas rurais. Logo, sem essa aplicação, o atendimento ficaria extremamente oneroso, podendo inclusive não ser realizado, o que levaria a um prejuízo maior do que as eventuais limitações do teleatendimento. Por outro lado, deve-se ficar a atento para que novas tecnologias não tragam ainda mais exclusão, pois se sabe que o acesso da população em geral aos meios teleinformáticos ainda é precário, clamando por ações efeitvas do Estado.

O parecer emitido pelo Conselho Federal de Medicina, a partir do Processo-Consulta ${ }^{0}$ 2501/10, apesar não ter mais o seu conteúdo axiológico referendado nos atuais posicionamentos do mesmo conselho de classe, demonstra que os diferentes casos que se apresentam em juízo devem ter o tratamento desigual na medida das suas desigualdades. Deve o médico e o periciando decidirem se é ou não o caso de se realizar a perícia por videoconferência; não se tratando, pois de questão puramente ética e sujeita ao controle absoluto da autarquia de fiscalização profissional.

Portanto, é possível acompanhar o parecer proferido nos autos do Processo-Consulta CFM no 2501/10, no sentido de que é ética e legal a realização de videoconferência em perícias médicas, nos limites circunstanciais da consulta, em situações de dificuldades de acesso à perícia presencial. Em especial, na psiquiatria forense, a teleperícia seria tecnicamente factível e razoável nos casos de extrema necessidade, como o atual isolamento social decorrente da pandemia 
de COVID-19, pois baseia-se, sobretudo, na entrevista e observação do exame do estado mental

Deve-se, contudo, garantir ao paciente, se assim o requerer, o direito de opção o exame presencial quando este for possível. De outro lado, os médicos que realizam as perícias judiciais não podem ser compelidos a aceitar a modalidade teleperícia que lhes é imposta. Valendo-se de critérios científicos e motivando a sua renúncia ao encargo, o profissional pode se recusar a realizar a perícia nos moldes que lhe foram propostos, tendo respaldo nos primados constitucionais que regem o livre exercício profissional, nos preceitos e normas do seu Código de Ética, bem como no art. $1^{\circ}, \S 2^{\circ}$, da Resolução $n^{0} 317 / 2020$ do CNJ.

Data de Submissão: 03/06/2020

Data de Aprovação: 22/10/2020

Processo de Avaliação: double blind peer review

Editor Geral: Jailton Macena de Araújo

Editor de Área: Alana Ramos Araujo

Assistente Editorial: Maria Aurora Medeiros

\section{REFERÊNCIAS}

ABMLPM. Nota técnica de esclarecimento sobre aplicação de telemedicina em medicina legal e perícias médicas.

Disponível em: https://abmlpm.org.br/wpcontent/uploads/2020/o4/Nota-sobre-Telemedicina-na-MedicinaLegal-e-Pericias-M\%C3\%A9dicas-2020.pdf. Aesso em: 01 mai. 2020.

ALMEIDA, E. H. R. de. Perícia e especialidades médicas. Disponível em:

http://portal.cfm.org.br/index.php?option=com_content\&view=arti cle\&id=26828:2017-03-31-18-05-49\&catid=46. Acesso em 29 abr. 2020. 
O Mundo Do Trabalho Em Tempos De Pandemia No Brasil: 0 Incremento Da...

ANTONACCI, D. J., BLOCH, R. M., SAEED, S. A., et al, Empirical evidence on the use and effectiveness of telepsychiatry via videoconferencing: Implications for forensic and correctional psychiatry. Behavioral Sciences \& the Law, 26(3), p. 253-269, 2008.

ARANTES, R.L. Telepsiquiatria: Breve Panorama Mundial. In: Anais do CBIS'2002 - VIII Congresso Brasileiro de Informática em Saúde Natal/RN - 29 de setembro a 02 de outubro de 2002. "A Realidade Brasileira e Caminhos para o Futuro".

BRASIL. Lei no 13.989, de 15 de abril de 2020. Dispõe sobre o uso da telemedicina durante a crise causada pelo coronavírus (SARSCoV-2). Diário Oficial da União; República Federativa do Brasil, Seção 1, 16 abr. 2020.

\section{CONSELHO FEDERAL DE MEDICINA. Parecer CFM no} 45/2016. Disponível em:

https://sistemas.cfm.org.br/normas/arquivos/pareceres/BR/2016/4 5_2016.pdf. Acesso em 17 de mai. de 2020.

CONSELHO FEDERAL DE MEDICINA. Parecer no $3 / 2020$. Disponível em: https://sistemas.cfm.org $\mathrm{br} /$ normas/visualizar/pareceres/BR/2020/3. Acesso em 01 mai. 2020.

CONSELHO FEDERAL DE MEDICINA. Resolução CFM no 1.643/2002. Disponível em: https://sistemas.cfm.org.br/normas/visualizar/resolucoes/BR/2002 /1643. Acesso em 31 mai. 2020.

CONSELHO FEDERAL DE MEDICINA. Resolução CFM no 1.821/2007. Disponível em:

http://www.portalmedico.org.br/resolucoes/CFM/2007/1821_2007. pdf. Acesso em 01 mai. 2020.

CONSELHO FEDERAL DE MEDICINA. Resolução CFM no1.931/o9. Disponível em: http://portal.cfm.org.br/images/stories/biblioteca/codigo\%2ode\%2 oetica\%20medica.pdf. Acesso em 01 mai. 2020.

CONSELHO NACIONAL DE JUSTIÇA, Resolução CFM na 317/2020. Disponível em:

http://ajufe.org.br/images/pdf/Resoluc\%CC\%A7a\%CC\%830_CNJ_t eleperi\%CC\%81cia.pdf. Acesso em: 31 de mai. 2020.

FRANÇA, G. V. Medicina Legal. 10 ${ }^{\text {a }}$ ed. Rio de Janeiro: Guanabara Koogan, 2015. 
GARRIDO, R. G. e PORTES, M. A. de A. Perito ou testemunha: Dilema entre a ampla defesa e a importação descontextualizada da testemunha técnica. Revista Eletrônica do Curso de De Direito da UFSM, v.11, n.3, p. 974-998, 2016.

GARRIDO, R.G, e GARRIDO, F.S.R.G. COVID-19: Um Panorama com Ênfase em Medidas Restritivas de Contato Interpessoal.

Interfaces Científicas-Saúde e Ambiente, 8, p. 127-141, 2020.

GARRIDO, R.G. e MOREIRA, B. S. P. Influência da perícia psiquiatrica nas sentenças previdenciárias em juizados especiais federais. Revista Brasileira de Previdência, v. 1, p. 96-103, 2020.

GOMES, H. Medicina Legal. $33^{\mathrm{a}}$ ed. Rio de Janeiro: Freitas Bastos, 2004 .

GOROSTIZA, P. R.; MANES, J. A. Misunderstanding psychopathology as medical semiology: an epistemological enquiry. Psychopathology, vol. 44, n. 4, p. 205-215, 2011.

HELZER, J. E. The use of a structured diagnostic interview for routine psychiatric evaluations. The Journal of nervous and mental disease, vol. 169, n. 1, p. 45-49, 1981.

LEITE, H. M.; LEITE, J. S. de S. e GARRIDO, R. G. O valor probatório da assistência técnica. Revista da Faculdade de Direito, n. 38, p. 277-289, 2018.

LOSS, M. M. M.; BOFF, S. O. A Possibilidade de Potencialização do Acesso ao Direito Fundamental à Previdência Social por meio das Novas Tecnologias. Prim Facie, v. 14, n. 27, p. 01-30, 20 fev. 2016.

LOYOLA, Carlos Augusto Maranhão et al. Curso de perícia judicial previdenciária. Coordenação José Antônio Savaris- 3.ed.Curitiba: Alteridade, 2018.

\section{MACEDO, A. da C. Benefícios previdenciários por} incapacidade e perícias médicas: teoria e prática. Curitiba: Juruá, 2017.

MALDONADO, J. M. S. de V.; MARQUES, A. B. e CRUZ, A. Telemedicina: desafios à sua difusão no Brasil. Cadernos de Saúde Pública, v. 32, p. eoo155615, 2016.

MARINONI, L.G. Novo curso de processo civil: tutela dos direitos mediante procedimento comum, Vol.II, São Paulo: Revista dos Tribunais, 2015. 
O Mundo Do Trabalho Em Tempos De Pandemia No Brasil: 0 Incremento Da...

MARS, M.; RAMLALL, S. e KALISKI, S. Forensic telepsychiatry: a possible solution for South Africa? African journal of psychiatry, v. 15, n. 4, 2012.

MARTIN, D. C. The mental status examination. In: WALKER, H. K., HALL, W. D., HURST, J. W. (eds) Clinical Methods: The History, Physical, and Laboratory Examinations. 3rd ed. Boston: Butterworths; Chapter 207, 1990.

MILLER, T. W.; CLARK, J.; VELTKAMP, L. J. et al. Teleconferencing Model for Forensic Consultation, Court Testimony, and Continuing Education. Behav Sci Law, 26, 3, p. 301-313, 2008.

\section{MINISTÉRIO PÚBLICO FEDERAL. Ofício}

128/2020/PFDC/MPF. Disponível em:

http://www.mpf.mp.br/pfdc/manifestacoes-pfdc/oficios/oficio-1282020-pfdc-mpf/view. Acesso em: 01 mai. 2020.

MINISTÉRIO PÚBLICO FEDERAL. Recomendação 4/2020/PFDC/MPF. Disponível em: http://www.mpf.mp.br/pfdc/manifestacoes$\mathrm{pfdc} /$ recomendacoes/recomendacao-4-2020-pfdc-mpf/view. Acesso em: 01 mai. 2020.

NAKANO, S.M.S.; RODRIGUES FILHO, S.; SANTOS, I.C. Perícia médica. Conselho Federal de Medicina, Conselho Regional de Medicina do Estado de Goiás, Brasília DF. 2012.

NETO, H. G. R et al. Mental State Examination and Its ProceduresNarrative Review of Brazilian Descriptive

Psychopathology. Frontiers in psychiatry, vol. 10, 2019.

OMS. Telemedicine: Opportunities and developments in Member States. Disponível em:

https://www.who.int/goe/publications/goe_telemedicine_2010.pdf. Acesso em: 04 de mai. 2020.

SALES, C. P.; MCSWEENEY, L; SALEEN, Y et al. The use of telepsychiatry within forensic practice: a literature review on the use of videolink - a tenyear follow-up. The Journal of Forensic

Psychiatry \& Psychology, vol. 29, p. 387-402, 2017.

SARTORI, R. R. V. e BIALLE, L. O instituto da Recomendação. Revista Jurídica do MP-PR, n. 5, p. 329-371, 2016

TABORDA, J.G.V.; CHALUB, M. e ABDALA-FILHO, E. (org).

Psiquiatria forense. Porto Alegre: Artmed; 2004.

TSIRINTANI, M.; ANDRIKOPOULOU, L. e BINIORIS, S.

Contemporary Telemedicine Applications in the Provision 
of Mental Health Services in Greece. In: KAVOURA, A.; KEFALLONITIS, E e THEODORIDIS, P. (Eds.). Strategic Innovative Marketing and Tourism. Springer, Cham, 2020. p. 393401.

WEN, C. L. Telemedicina e telessaúde-um panorama no Brasil. Informática Pública, v. 10, n. 2, p. 7-15, 2008.

ZUARDI, A.W.; LOUREIRO, S. R. Semiologia psiquiátrica. Medicina (Ribeirao Preto Online), v. 29, n. 1, p. 44-53, 1996. 
O Mundo Do Trabalho Em Tempos De Pandemia No Brasil: 0 Incremento Da...

Controverted Use Of Forensic Telemedicine In Times Of Social Isolation By The Covid-19 Pandemic

\author{
Alan da Costa Macedo
}

Bruno da Silveira Pataro Moreira

Rodrigo Grazinoli Garrido

\begin{abstract}
This article aims to present some logical-inductive reflections based on the norms of the forensic sciences, especially the judicial forensic medicine related to the granting of social security benefits due to disability in times of social isolation by pandemic of COVID-19. The possibility of using the forensic telemedicine institute is analyzed, especially in psychiatry, in the light of the current normative commands and of the organs and authorities linked to the Judiciary as opposed to the guidelines of the Federal Council of Medicine. It started from the understanding of forensic medicine as a means of proof and therefore, with matters regulated primarily by Civil Procedural Law and the Federal Constitution. In the results obtained, it was concluded that it is legal and ethical, in addition to being technically possible in various cases, the use of forensic telemedicine in situations that impose barriers that hinder access to the face-to-face examination, being the responsibility of the medical expert and the examining the option to perform forensic telemedicine.
\end{abstract}

Keywords: Forensic psychiatry. Forensic in social security. Technical evidence. COVID-19. 